\title{
PENGUKURAN KINERJA METODE PERAMALAN TIPE EXPONENTIAL SMOOTHING DALAM PARAMETER TERBAIKNYA
}

\author{
Maftahatul Hakimah ${ }^{1)}$, Weny Mistarika Rahmawati ${ }^{2)}$, Andre Yuldian Afandi ${ }^{3)}$ \\ 1), 2),3) Jurusan Teknik Informatika, Fakultas Teknik Elektro Dan Teknologi Informasi, Institut \\ Teknologi Adhi Tama Surabaya \\ Jl Arief Rachman Hakim 100 Surabaya \\ Email : hakimahmafta@gmail.com ${ }^{1)}$, $\underline{\text { wenymistarika@gmail.com }}^{2}$, andreyuldian7@gmail.com $^{3)}$
}

\begin{abstract}
Abstrak
Tipe exponential smoothing yang dikaji pada penelitian ini adalah simple exponential smoothing, double exponential smoothing, double exponential smoothing dengan damped trend dan triple exponential smoothing. Tujuan dari penelitian ini adalah ingin mengetahui kinerja tipe exponential smoothing yang paling baik dalam meramalkan nilai tengah tukar harian rupiah terhadap USD. Kinerja metode peramalan tipe exponential smoothing sangat bergantung pada pemilihan nilai parameter pemulusan yang terkandung pada persamaan matematikanya. Oleh karena itu, nilai parameter terbaik untuk setiap tipe exponential smoothing akan dicari menggunakan program solver. Mendapatkan nilai parameter terbaik merupakan permasalahan optimasi. Pada penelitian ini, masalah optimasi nilai parameter ini adalah meminimalkan kesalahan peramalan berdasarkan MAPE dengan fungsi kendalanya adalah persamaan peramalan untuk setiap tipe exponential smoothing. Tahapan penelitian dibagi menjadi 2 segmen yaitu tahap pelatihan dan tahap pengujian. Tahap pelatihan menghasilkan nilai parameter pemulusan terbaik. Nilai parameter terbaik kemudian dijadikan sebagai input untuk tahap pengujian. Tahap pengujian ini untuk mengetahui kinerja masing-masing tipe exponential smoothing. Kinerja tipe exponential smoothing diukur berdasarkan besarnya kesalahan peramalan menggunakan MAPE, MAD dan RMSE. Hasil pengujian menunjukkan bahwa kinerja metode double exponential smoothing dengan damped trend paling baik dibandingkan tipe exponential yang lain dengan MAPE $=0.840, M A D=117.28$ dan $R M S E=186.07$.
\end{abstract}

Kata kunci: Exponential smoothing, damped trend, Solver.

\section{Abstract}

The types of exponential smoothing studied in this study are simple exponential smoothing, double exponential smoothing, double exponential smoothing with damped trend and triple exponential smoothing. The purpose of this study is to find out the best exponential smoothing type performance in predicting the daily exchange rate of the rupiah against the USD. The performance of the exponential smoothing type forecasting method is very dependent on the selection of the smoothing parameter values contained in the mathematical equation. Therefore, the best parameter values for each type of exponential smoothing will be searched using the solver program. Getting the best parameter values is an optimization problem. In this study, the problem of optimizing the value of this parameter is to minimize forecasting errors based on $M A P E$ with the constraint function is the forecast equation for each type of exponential smoothing. The stages of the study were divided into 2 segments, namely the training phase and the testing phase. The training phase produces the best smoothing parameter values. The best parameter values are then used as input for the testing phase. This testing phase is to determine the performance of each type of exponential smoothing. Exponential smoothing type performance is measured based on the magnitude of forecasting errors using MAPE, MAD and RMSE. The test results show that the performance of the double exponential smoothing method with the best damped trend compared to other exponential types with MAPE $=0.840$, $M A D=117.28$ and $R M S E=186.07$.

Keywords :Exponential smoothing, damped trend, Solver.

\section{PENDAHULUAN}

Exponential smoothing adalah salah satu metode peramalan untuk data deret waktu. Model peramalan tipe exponential smoothing ini dipilih berdasarkan komponen yang terkandung pada data yang dikaji. Komponen data yang dimaksud disini adalah unsur tren dan unsur 44 | N E R O 
musiman. Ada 3 tipe exponential smoothing yaitu simple exponential smoothing (SES), double exponential smoothing (DES) dan triple exponential smoothing (TES). Tipe SES dipilih untuk data yang bebas dari pola tren atau musiman, DES sangat baik untuk meramalkan data yang mengandung unsur tren [1] sedangkan TES digunakan untuk meramalkan data yang mengandung pola musiman [2],[3]. Selain itu, pada tipe DES diberikan parameter tambahan untuk meredam pergerakan tren yang disebut dengan damped holt's methods (DES dengan damped trend) [2]. Tipe exponential smoothing ini pernah dibandingkan pada penelitian sebelumnya [1], [4], [5]. Penelitian ini akan mengukur kinerja metode peramalan tipe exponential smoothing yaitu, SES, DES, TES dan DES dengan Damped Trend. Data penelitian yang digunakan adalah data harian nilai tengah tukar rupiah terhadap USD selama tahun 2019 dan Awal Tahun 2020.

Kinerja metode peramalan tipe exponential smoothing sangat dipengaruhi oleh pemilihan parameter pemulusan yang ada dalam persamaan matematikanya [6],[7]. Model SES dipengaruhi oleh parameter pemulusan tunggal, model DES dipengaruhi oleh dua parameter pemulusan, model TES dipengaruhi oleh tiga parameter pemulusan sedangkan model DES dengan damped trend dipengaruhi oleh 2 parameter pemulusan dan 1 parameter peredaman tren. Pemilihan parameter terbaik umumnya dicari dengan uji coba sedemikian hingga kesalahan peramalan sangat kecil [2],[8],[6],[9],[5]. Penelitian ini menggunakan menu "solver" yang terdapat pada excel untuk mendapatkan nilai terbaik untuk parameter yang terkandung pada setiap tipe exponential smoothing tersebut. Program Solver ini termasuk salah satu aplikasi penyelesaian masalah optimasi. Parameter terbaik diperoleh dengan menjadikan kesalahan peramalan sebagai fungsi obyektif dan persamaan pada masing-masing tipe exponential dijadikan sebagai fungsi kendala (konstrain). Program Solver ini pernah digunakan oleh Nazim untuk mendapatkan parameter terbaik tipe exponential smoothing dalam meramalkan populasi penduduk Malaysia[4]. Dengan diketahui parameter terbaik dari tipe exponential smoothing, akan diketahui model peramalan yang paling cocok untuk data yang dikaji. Dengan spesifikasi yang berbeda dari tipe exponential smoothing, ketiga metode ini sepertinya tidak sepadan jika dibandingkan.Namun,karena data harian nilai tengah tukar rupiah terhadap USD sangat fluktuatif maka pertimbangan adanya komponen tren dan musiman pada data yang dikaji bisa dilihat salah satunya dari besarnya kesalahan hasil peramalan yang diperoleh untuk setiap tipe exponential smoothing. Pengukuran kesalahan ini akan dilakukan pada tahap pengujian metode peramalan.

\section{DASAR TEORI}

\section{a. Simple Exponential smoothing}

Exponential smoothing yang paling sederhana umumnya dikenal dengan simple exponential smoothing (SES). Metode ini sangat cocok untuk data yang bersih dari tren dan pola musiman. Persamaan matematika untuk tipe SES adalah [2] :

Pemulusan data

$$
\begin{gathered}
: \ell_{t}=\alpha y_{t}+(1-\alpha) \ell_{t-1} \quad ; 0 \leq \alpha \leq 1 \\
: \hat{y}_{t+h \mid t}=\ell_{t}
\end{gathered}
$$

Rumus Peramalan

dengan,

$\ell_{t} \quad$ : Nilai ramalan pada periode $t$

$y_{t} \quad$ : Nilai aktual pada periode $t$

$\alpha \quad$ : Alpha, parameter pemulusan

$\hat{y}_{t+h \mid t}:$ Nilai peramalan untuk $h$ periode kedepan

Kinerja metode SES sangat dipengaruhi oleh alpha dan inisialisasi $l_{0}$. Pada makalah ini, nilai $l_{0}$ adalah rata-rata nilai tengah tukar rupiah selama periode bulan januari 2019.

\section{b. DoubleExponential smoothing}

Pada tahun 1957, Holt mengembangkan SES untuk mempertimbangkan data peramalan yang mengandung tren. Metode ini memuat persamaan peramalan dan dua persamaan pemulusan yaitu pemulusan data dan pemulusan tren sehingga dinamakan doubleexponential smoothing (DES). Persamaan DES diberikan berikut ini [2]:

$$
\text { Pemulusan data : } \ell_{t}=\alpha y_{t}+(1-\alpha)\left(\ell_{t-1}+b_{t-1}\right) \quad ; 0 \leq \alpha \leq 1
$$


Pemulusan tren : $b_{t}=\beta\left(\ell_{t}-\ell_{t-1}\right)+(1-\beta) b_{t-1} \quad ; 0 \leq \beta \leq 1$

Rumus Peramalan $: \hat{y}_{t+h \mid t}=\ell_{t}+h b_{t}$

dengan,

$b_{t} \quad$ : Estimasi tren pada periode $t$

$\beta \quad$ : Beta, parameter pemulusan tren

Kinerja metode DES sangat dipengaruhi oleh pemilihan alpha dan beta serta inisialisasi untuk $l_{0}$ dan $b_{0}$. Makalah ini memberi nilai awal $l_{0}$ dan $b_{0}$ dengan intercept dan slope yang diperoleh dengan cara regresi linier untuk 1 bulan pertama pada data penelitian.

\section{c. Double Exponential Smoothing Dengan Damped Trend}

Peramalan yang dihasilkan oleh metode DES menampilkan tren yang konstan tanpa batas. Sehingga peramalan yang dihasilkan berlebihan terutama untuk horizon peramalan jangka panjang. Dari pengamatan ini, pada Tahun 1985 Gardner \& Mc Kenzie memperkenalkan parameter yang meredam tren ke garis datar beberapa periode dimasa depan. Metode ini terbukti sukses untuk peramalan jangka panjang. Persamaan matematika metode DES dengan damped trend diberikan berikut ini [2].

$$
\begin{array}{ll}
\text { Pemulusan data }: \ell_{t}=\alpha y_{t}+(1-\alpha)\left(\ell_{t-1}+\varphi b_{t-1}\right) & ; 0 \leq \alpha \leq 1 \\
\text { Pemulusan tren }: b_{t}=\beta\left(\ell_{t}-\ell_{t-1}\right)+(1-\beta) \varphi b_{t-1} & ; 0 \leq \beta \leq 1 \\
\text { Rumus Peramalan : } \hat{y}_{t+h \mid t}=\ell_{t}+\left(\varphi+\varphi^{2}+\ldots+\varphi^{h}\right) b_{t} &
\end{array}
$$

Dengan $\varphi$ adalah parameter peredaman dan nilainya berkisar dari 0 sampai 1 . Sehingga kinerja metode ini sangat dipengaruhi oleh dua parameter pemulusan dan satu parameter peredaman. Inisialisasi metode ini sama dengan tipe DES. Selanjutnya, metode DES dengan damped trend disingkat menjadi DT.

\section{d. Triple Exponential Smoothing}

Pada tahun 1960, Winter mengembangkan metode Holt (DES) dengan mempertimbangkan musiman. Metode ini kemudian dinamakan metode Holt-Winters atau dalam makalah ini disebut tripleexponential smoothing (TES). Pada metode ini, frekuensi musiman $m$ harus ditentukan. Misalnya, dalam satu tahun musiman bisa ditentukan setiap 3 bulan sekali ( $m$ $=4)$ atau bisa juga ditentukan musiman terjadi pada setiap bulan $(\mathrm{m}=12)$.

Ada dua variasi yang berbeda pada TES untuk sifat komponen musiman yaitu metode additive dan metode multiplikatif. Metode Additive lebih disukai ketika variasi musiman konstan pada deret data sedangkan metode multiplikatif lebih disukai ketika variasi musiman berubah secara proporsional dalam deret data. Pada makalah ini, metode TES yang dipilih adalah metode additive yang diberikan oleh persamaan berikut ini [2] :

$$
\begin{aligned}
& \text { Pemulusan data : } \ell_{t}=\alpha\left(y_{t}-s_{t-m}\right)+(1-\alpha)\left(\ell_{t-1}+b_{t-1}\right) \\
& \text { Pemulusan tren : } b_{t}=\beta\left(\ell_{t}-\ell_{t-1}\right)+(1-\beta) b_{t-1} \quad ; 0 \leq \beta \leq 1 \\
& \text { Pemulusan musiman: } s_{t}=\gamma\left(y_{t}-\ell_{t-1}-b_{t-1}\right)+(1-\gamma) s_{t-m} ; 0 \leq \gamma \leq 1 \\
& \text { Rumus Peramalan : } \hat{y}_{t+h \mid t}=\ell_{t}+h b_{t}+s_{t+h-m}(k+1) \\
& \text { dengan, } \\
& s_{t} \quad \text { : Perkiraan musiman pada periode } \mathrm{t} \\
& \gamma \quad \text { : gamma, parameter pemulusan musiman } \\
& k \text { : bilangan bulat yang memastikan bahwa perkiraan indeks musiman yang digunakan } \\
& \text { untuk peramalan berasal dari periode terakhir data sampel }
\end{aligned}
$$

Kinerja metode TES sangat dipengaruhi oleh parameter pemulusan gamma dan inisialisasi dari $l_{0}, b_{0}$ dan $s_{0}, s_{-1}, \ldots, s_{1-m}$. Nilai yo dan $b_{0}$ diberi nilai sama seperti pada DES sedangkan $s_{0}, s_{-1}, \ldots, s_{1-m}$ ditentukan dari indeks musiman pada 1 bulan pertama pada data penelitian.

\section{e. Evaluasi Model Peramalan}


Kinerja model peramalan sangat penting untuk dievaluasi sebagai tahap validasi model yang cocok untuk data penelitian [3]. Kinerja model peramalan pada makalah ini dilihat berdasarkan kesalahan peramalan yang dihasilkan. Kesalahan model peramalan tipe exponential smoothing pada makalah ini menggunakan 3 pengukuran yaitu [10],

- Mean Absolute Deviation ( MAD )

$$
M A D=\frac{1}{n} \sum_{t=1}^{n}\left|e_{t}\right|
$$

dengan $e_{t}$ : selisih antara nilai aktual dengan nilai ramalan pada saat periode $t$

- Mean Absolute Percentage Error ( MAPE )

$$
M A P E=\frac{1}{n} \sum_{t=1}^{n} \frac{\left|e_{t}\right|}{y_{t}} \times 100
$$

- $\quad$ Root Mean Square Error ( RMSE )

$$
R M S E=\sqrt{\frac{1}{n} \sum_{t=1}^{n}\left(e_{t}\right)^{2}}
$$

\section{METODOLOGI PENELITIAN}

Data yang digunakan pada makalah ini adalah nilai tengah tukar rupiah terhadap USD dengan periode harian yaitu 1 Januari 2019 sampai dengan 28 Februari 2020. Data diperoleh dari situs resmi Bank Indonesia yaitu laman bi.go.id. Gambar 1 berikut ini menunjukkan grafik nilai tengah tukar rupiah terhadap USD pada periode tersebut.

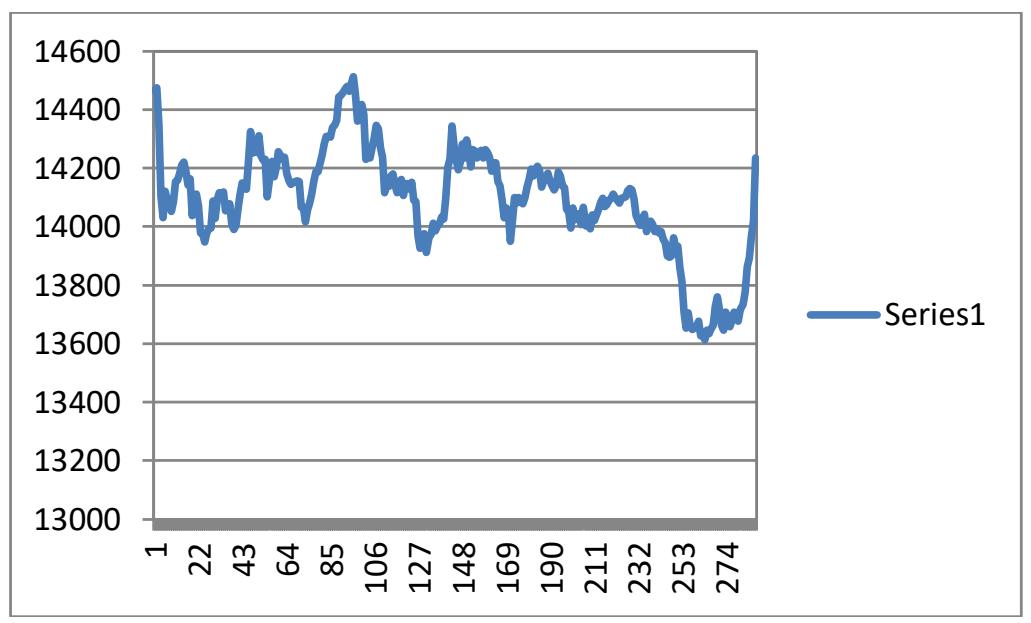

Gambar 1. Nilai Tengah Kurs Transaksi BI

Data penelitian pada Gambar 1 mempunyai unsur tren. Gambar 2 berikut ini menunjukkan adanya tren linier pada data.

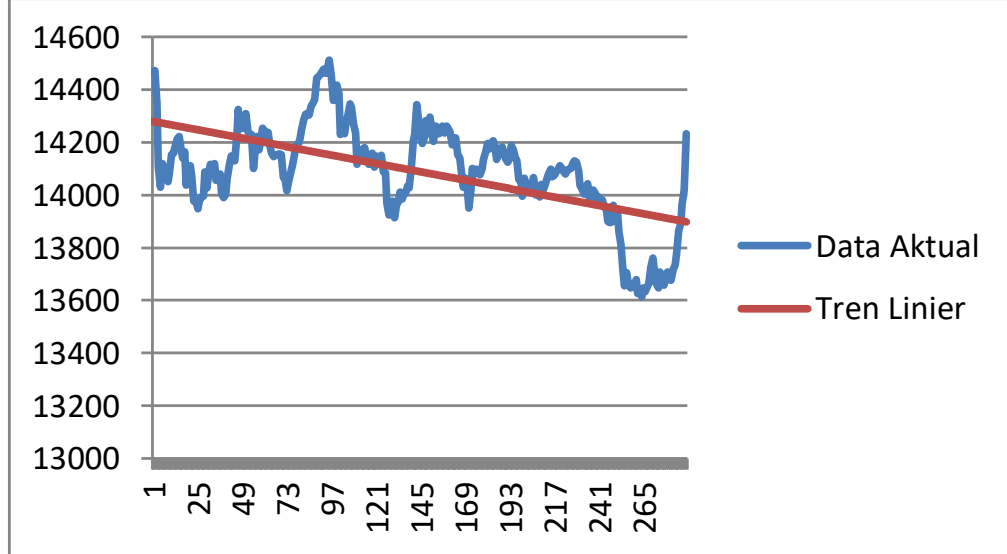

Gambar 2. Tren linier pada data nilai tengah tukar rupiah terhadap USD 
Tren linier yang ada pada data menunjukkan bahwa nilai tengah tukar rupiah terhadap USD pada Tahun 2019 sampai dengan awal Tahun 2020 cenderung menguat. Pada makalah ini, metode peramalan tipe exponential smoothing akan diukur kinerjanya dalam meramalkan nilai tengah tukar rupiah terhadap USD. Untuk tujuan tersebut maka data penelitian akan dibagi menjadi 2 bagian yaitu data latih dan data uji yang diberikan pada Tabel 1 berikut ini:

Tabel 1. Segmentasi Data

\begin{tabular}{|l|l|l|}
\hline Data Penelitian & Periode & Jumlah Data \\
\hline Data Latih & 01 Januari 2019 - 31 Januari 2020 & 268 \\
\hline Data Uji & 3 Februari - 28 Februari 2020 & 20 \\
\hline
\end{tabular}

Data latih digunakan untuk mendapatkan parameter pemulusan terbaik berdasarkan besarnya ukuran kesalahan peramalan. Pada makalah ini, parameter terbaik dicari dengan program Solver yang tersedia di excel. Mendapatkan parameter terbaik merupakan masalah optimasi. Penentuan model optimasi pada makalah ini adalah :

Minimasi : Persamaan (14)

dengan kendala untuk masing-masing tipe exponential smoothing berikut :

SES :Persamaan (1) - (2),

DES : Persamaan (3) $-(5)$,

DT : Persamaan $(6)-(8)$,

TES : Persamaan (9) - (12),

Selanjutnya, parameter pemulusan terbaik yang diperoleh diterapkan untuk meramalkan data uji. Kinerja terbaik dari tipe exponential smoothing diukur berdasarkan kesalahan peramalan data uji dengan menggunakan Persamaan (13) - (15).

\section{HASIL DAN PEMBAHASAN}

Metode peramalan tipe exponential smoothing sangat dipengaruhi oleh parameter pemulusannya. Banyak kemungkinan menentukan parameter danatau kombinasi parameter agar peramalan yang dihasilkan mempunyai kesalahan yang kecil. Dalam makalah ini, program solver pada microsoft excel diterapkan untuk mendapatkan parameter terbaik pada masing-masing tipe exponential smoothing. Kinerja tipe exponential smoothing dalam meramalkan data harian nilai tengah tukar rupiah terhadap USD dikaji dengan dua tahap yaitu tahap pelatihan dan tahap uji. Tahap pelatihan bertujuan untuk mendapatkan parameter terbaik dengan menerapkan peramalan pada data latih. Kinerja tipe exponential smoothing diukur berdasarkan kesalahan peramalan pada tahap uji. Berikut ini adalah parameter terbaik untuk masing-masing tipe exponential smoothing pada tahap pelatihan data.

Tabel 2. Parameter Terbaik masing-masing tipe exponential smoothing

\begin{tabular}{|l|l|l|l|l|}
\hline Parameter & Alpha & Beta & Damped & Gamma \\
\hline SES & 0.8295 & - & - & - \\
\hline DES & 0.8784 & 0.0259 & - & - \\
\hline DT & 0.8637 & 0.0647 & 0.0186 & - \\
\hline TES & 0.8239 & 0.0278 & - & 0.0703 \\
\hline
\end{tabular}

Tabel 2 menunjukkan semua tipe exponential smoothing memberikan bobot yang hampir sama terhadap data terbaru yang berkisar pada nilai 0.8. Pencocokan kurva antara data aktual dengan hasil peramalan pada semua tipe exponential smoothing diberikan pada grafik Gambar 3 berikut ini. 


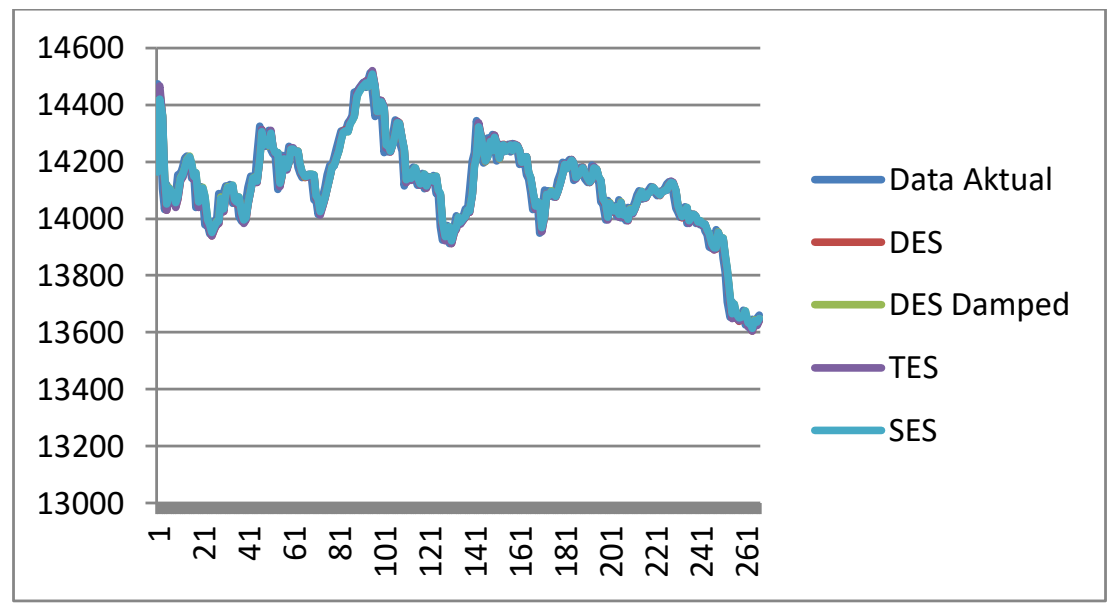

Gambar 3. Pencocokan Kurva Data Latih

Gambar 3 menunjukkan nilai parameter yang terbaik pada masing-masing tipe exponential smoothing yang dikaji diperoleh dari mempelajari pola data aktual. Nilai parameter terbaik yang disajikan pada Tabel 2 akan dijadikan input pada tahap pengujian. Tahap pengujian merupakan tahap untuk mengukur kinerja peramalan tipe exponential smoothing. Kinerja peramalan diukur berdasarkan besarnya kesalahan peramalan yang dihasilkan pada masingmasing tipe exponential smoothing. Kesalahan peramalan diukur berdasarkan MAD, MAPE dan RMSE. Tabel 3 berikut ini merupakan hasil dari tahap pengujian.

Tabel 3.Pengukuran Kesalahan Peramalan Tipe Exponential smoothing

\begin{tabular}{|l|l|l|l|}
\hline Pengukuran & MAD & MAPE & RMSE \\
\hline SES & 117.70 & 0.844 & 186.401 \\
\hline DES & 187.81 & 1.350 & 257.438 \\
\hline DT & 117.28 & 0.840 & 186.070 \\
\hline TES & 187.17 & 1.345 & 257.812 \\
\hline
\end{tabular}

Pengukuran kesalahan yang diberikan pada Tabel 3 menunjukkan bahwa tipe DT paling baik kinerjanya dalam meramalkan nilai nilai tengah tukar rupiah terhadap USD dalam periode harian. Pencocokan kurva hasil peramalan tipe exponential smoothing dengan data aktual diberikan pada Gambar 4 berikut ini.

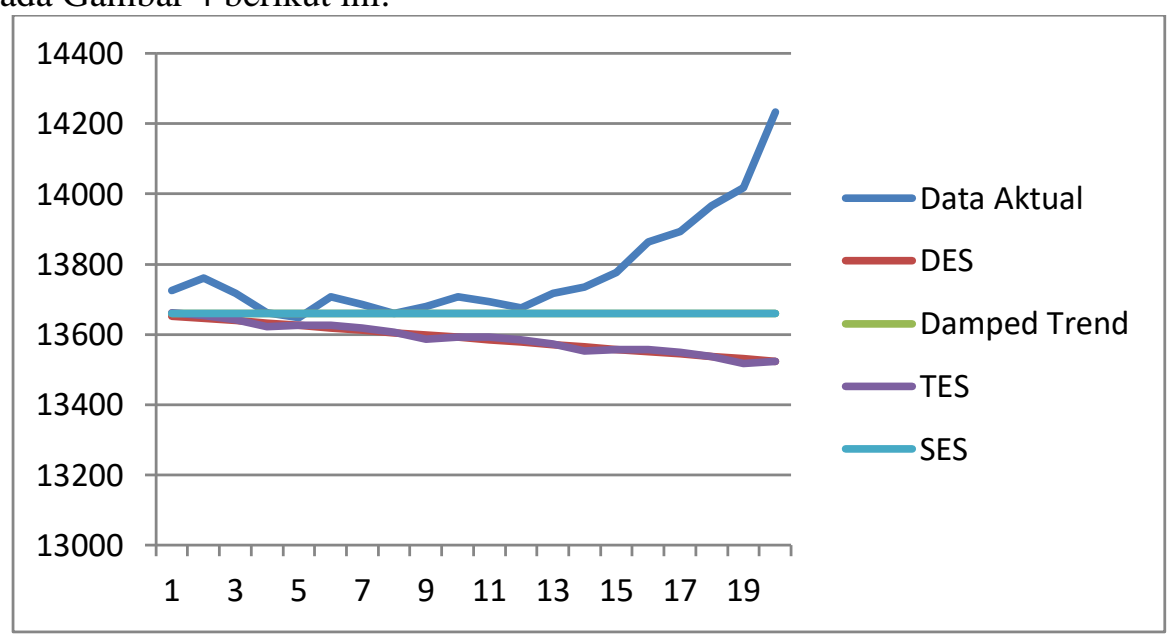

Gambar 3. Pencocokan Kurva Data Uji Terhadap Data Aktual

Gambar 3 menunjukkan bahwa hasil peramalan tipe exponential smoothing makin menjauh dari data aktual yaitu pada saat kondisi rupiah melemah (kurva data aktual mengalami kenaikan). Hasil peramalan ini sangat dipengaruhi oleh pola data histori yang dipelajari pada tahap pelatihan. Karena tahap pelatihan mengenali adanya tren menurun maka hasil peramalan tipe exponential smoothing pun menunjukkan tren menurun. Gambar 3 menunjukkan hasil peramalan DT paling mendekati kurva data aktual dibandingkan DES yang makin menjauh dari data aktual. Oleh karena itu, pertimbangan adanya faktor peredaman tren (damped trend) dapat 
memperbaiki kinerja DES. Selain itu, jika dibandingkan hasil peramalan antara SES, DES dan TES maka SES paling baik kinerjanya. Hasil perbandingan ketiga metode exponential smoothing tersebut merekomendasikan bahwa nilai tengah tukar rupiah selama tahun 2019 dan awal Tahun 2020 tidak dipengaruhi tren dan musiman.

\section{KESIMPULAN}

Metode peramalan tipe exponential smoothing telah diterapkan pada data nilai tengah tukar rupiah terhadap USD. Program solver telah digunakan untuk mendapatkan parameter yang terbaik dari masing-masing tipe exponential smoothing. Dengan parameter terbaik yang diperoleh, kinerja metode peramalan tipe exponential smoothing telah diukur berdasarkan besarnya kesalahan peramalan MAD, MAPE dan RMSE. Dari hasil pengujian, kesimpulan yang diperoleh adalah :

[1] Metode double exponential smoothing dengan damped trend menunjukkan paling baik kinerjanya dibandingkan tipe exponential smoothing lainnya dengan $\mathrm{MAD}=117.28$, MAPE $=0.840$ dan RMSE $=186.07$. Parameter terbaik untuk double exponential smoothing dengan damped trend adalah parameter pemulusan level $=0.8637$, parameter pemulusan tren $=0.0647$ dan parameter peredaman tren $=0.0186$.

[2] Hasil pengukuran yang menunjukkan metode simple exponential smoothing lebih baik dari double dan triple exponential smoothing dalam parameter terbaiknya merekomendasikan bahwa nilai tengah tukar rupiah terhadap USD di Tahun 2019 dan di Awal Tahun 2020 cenderung stabil tanpa ada pengaruh tren dan musiman.

\section{Daftar Pustaka}

[1] Hartono, "Perbandingan Metode single Exponential Smoothing Dan Metode Exponential Smoothing Adjusted For Trend (Holt's Method) Untuk Meramalkan Penjualan. Studi Kasus: Toko Onderdil Mobil 'Prodi, Purwodadi,'” J. EKSIS, vol. 5, no. 1, pp. 8-18, 2012.

[2] R. J. Hyndman and G. Athanasopoulos, Forecasting: Principles and Practice, 2nd ed. Melbourne, Australia: OTexts, 2018.

[3] D. C. Montgomery, C. L. Jennings, and M. Kulahci, Introduction to Time Series Analysis and Forecasting. Hoboken, New Jersey: John Wiley \& Sons, Inc., 2008.

[4] A. N. Aimran and A. Afthanorhan, "A comparison between single exponential smoothing (SES), double exponential smoothing (DES), holts (brown) and adaptive response rate exponential smoothing (ARRES) techniques in forecasting Malaysia population," Glob. J. Math. Anal., vol. 2, no. 4, p. 276, 2014.

[5] B. Putro, M. T. Furqon, and S. H. Wijoyo, "Prediksi Jumlah Kebutuhan Pemakaian Air Menggunakan Metode Exponential Smoothing ( Studi Kasus : PDAM Kota Malang )," J. Pengemb. Teknol. Inf. dan Ilmu Komput. Univ. Brawijaya, vol. 2, no. 11, pp. 4679-4686, 2018.

[6] E. Lesmana et al., "Comparison of Double Exponential Smoothing Holt and Fuzzy Time Series Methods in Forecasting Stock Prices ( Case Study : PT Bank Central Asia Tbk )," pp. 1615-1625, 2019.

[7] J. Heizer and B. Render, Principles Of Operations Management, Seventh. New Jersey: Pearson Prentice Hall, 2008.

[8] B. K. Khotimah, M. Laili, and B. D. Satoto, "Prediksi Persediaan Ikan Teri Menggunakan Exponential Smoothing Berbasis Ordered Weighted Aggregation," J. Ilm. NERO, vol. 1, no. 1, pp. 27-32, 2014.

[9] R. Ariyanto, D. Puspitasari, and F. Ericawati, "Penerapan Metode Double Exponential Smoothing Pada Peramalan Produksi Tanaman Pangan," J. Inform. Polinema, vol. 4, no. 1, p. 57, 2017.

[10] M. V. Shcherbakov, A. Brebels, N. L. Shcherbakova, A. P. Tyukov, T. A. Janovsky, and V. A. evich Kamaev, "A survey of forecast error measures," World Appl. Sci. J., vol. 24, no. 24, pp. 171-176, 2013. 